\title{
DEL AMOR Y LA POESÍA UN ACERCAMIENTO A LA POÉTICA DE OCTAVIO PAZ
}

\author{
Gustavo Solórzano Alfaro
}

\begin{abstract}
RESUMEN
Este ensayo es un acercamiento a la poética de Octavio Paz, vista como una búsqueda de conjunción de los opuestos. Para tales efectos, se analiza el concepto de analogía y cómo esta funciona en el discurso amoroso y en el discurso poético, pues ambos son considerados como intentos del ser humano por escapar del estado cultural y retornar a su estado primigenio.

Palabras clave: amor, analogía, lenguaje, Octavio Paz, poesía.
\end{abstract}

\begin{abstract}
This essay is an approach to the poetic of Octavio Paz, seen as a search of conjunction of the opposites. For this purpose, we analyze the analogy concept and how it works in the love speech and in the poetry speech, since both are considered as attempts of the human being to escape from the cultural state and return to his original one.

Key words: love, analogy, language, Octavio Paz, poetry.
\end{abstract}

\section{A manera de introducción}

Al escribir estos artículos y notas no me propuse sino reconocer, en la variedad de algunas obras que admiro, esta verdad común a todas.

Octavio Paz Advertencia a la $1^{\circ}$ ed. de 1957 de Las peras del olmo (1971a: 8)

El tema escogido para elaborar el presente trabajo es la relación existente entre el discurso poético y el discurso amoroso; específicamente, la presencia de dicha relación o analogía en los textos del escritor mexicano Octavio Paz. Así, la justificación del trabajo que

\footnotetext{
Gustavo Solórzano Alfaro. Magister Litterarum en Literatura Latinoamericana. Profesor de Lengua y Literatura de la Universidad Estatal a Distancia, San José, Costa Rica. Editor filológico y literario de la EUNED.

Correo electrónico: gsolorzano@uned.ac.cr
}

Recepción: 13- 7- 2007

Aceptación: 28- 8- 2007 
proponemos deberá escindirse, de algún modo, en dos vertientes, en dos preguntas: ¿por qué Octavio Paz? y ¿por qué el amor?

Construyamos las respuestas.

\section{1. De Octavio Paz}

La serpiente emplumada: la serpiente vuelta sobre sí misma: el tiempo circular: decir las palabras, nombrarlas: las palabras hablan de ellas mismas. Confluir de espacios y cronopios, fusión-conjunción: la historia es la voz interminable de la muerte.

El siglo XX observó, tímido y expectante, la caída del mito de la modernidad. Los últimos grandes narradores y poetas europeos dejaron sus textos inscritos en el período de entreguerras. Después: silencio. Europa ha pasado un doloroso proceso de reestructuración del cual todavía no se repone. Sin embargo, la tradición occidental se renueva; no ahí, justamente donde los grandes relatos habían sido derribados, sino en otra tierra, en otro espacio y en otro tiempo. Latinoamérica es uno de esos espacios de conjunción-disolución de los paradigmas, lo cual se puede observar en la mirada extrañada y el asombro de los españoles ante las "mágicas y extravagantes realidades"; por ende, es a la vez un espacio de génesis y aporía: utopía y destrucción marcan esta tierra.

La segunda mitad del siglo xx vio una renovación de la narrativa (y deberíamos decir de las poéticas) que se daban en América Latina. Paralelamente, Europa empezaba el tortuoso camino de auscultar su historia, de marcar aquellos puntos en los cuales poder asentar las bases de lo que había sido su manera de entender el universo en general. Es decir, Europa hacía un examen (¿de conciencia?). No otra cosa fue el trabajo "arqueológico" de Foucault o la deconstrucción derridiana.

La tradición del pensamiento europeo, ya fuera filosófico o ensayístico, llegó a un punto de clímax con autores como los citados. Sin embargo, América, que si bien es cierto renovaría la literatura, había carecido de un correlato sólido en el ámbito de las ideas. Fueron autores como Octavio Paz quienes se refirieron a este problema cuando plantearon las preguntas sobre la modernidad de nuestra literatura: América, inscrita en una manera ajena de entender las cosas, casi siempre quedó relegada de la producción de paradigmas para asumir, enfrentar o simplemente inventar un esquema particular de representación para eso que llamamos mundo, ser humano o realidad. El mismo Paz, en Corriente alterna, apunta: "Es un secreto a voces que la crítica es el punto flaco de la literatura latinoamericana (...), carecemos de un "cuerpo de doctrina" o doctrinas..." (1990a: 39).

No es sino hasta la llegada de autores como Jorge Luis Borges o Julio Cortázar que nuestra literatura empieza a ser moderna ${ }^{2}$. Esto no significa otra cosa que la asunción de nuevas maneras de ver, de percibir o de soñar: el tiempo y el espacio, la paradoja de la existencia humana, el lenguaje y la muerte: signos perpetuados, signos perdidos. Es aquí donde se entronca y surge el pensamiento de Octavio Paz. Un pensamiento tributario de las grandes corrientes europeas, pero con una profunda mirada a la cumbre de las pirámides y templos Aztecas: edificios derruidos, edificios modernos del Distrito Federal. Una de las constantes o términos que Paz utiliza es el de la conjunción. Mejor no se puede definir su pensamiento, su obra: un intento por reconciliar los contrarios. En él confluyen el budismo, Occidente, el romanticismo europeo, los Aztecas; huellas que conforman la vorágine del ser humano contemporáneo en un momento y lugar específicos y determinados: bellos y terribles: ajenos y lejanos. 
El pensamiento de Octavio Paz renueva, reinventa el lenguaje y la cultura y deja un aporte vital al pensamiento, uno de los más importantes y lúcidos que se hayan producido hasta ahora, una llama doble: poesía y ensayo: Eros del silencio, poesía del amor. Paz es un crítico de la modernidad con marcados acentos existencialistas, pero sin nihilismo. Paz hace eco de la visión trágica del ser humano proveniente de grandes pensadores europeos, o bien, de la visión posmoderna podríamos señalar: fin de la historia, muerte del hombre. Sin embargo, hay una diferencia: la crítica latinoamericana es una apuesta por repensar los grandes proyectos de la humanidad. Somos, más bien, esperanzados, y consideramos que no se consume el fuego de cada día, porque el ser humano sigue vivo sobre la faz de la tierra; sigue vivo... y aguardando: ensayo y poesía para entenderlo. La estética como una propuesta ética. Nos detenemos en la poesía.

Así, la extensa obra poética de Octavio Paz se ha caracterizado por ser un intento de pensarse a sí misma como metáfora del universo, devenir metatexto, metáfora de la literatura, creación poética que desfila ante nuestros ojos y pide ser observada. Es la poesía haciendo crítica: “...el poeta nombra a las palabras, más que a los objetos que éstas designan” (1990a: 5).

Para Paz, las palabras están allí para ser destruidas, exprimidas, "Dales la vuelta/ cógelas del rabo (chillen, putas)", dice en su poema "Las palabras" de Libertad bajo palabra (1998b: 125). En este sentido, el poeta mexicano comulga con las tradiciones literarias propias del siglo xx (e incluso anteriores, que él mismo llama modernas) y es quizá él, junto con el argentino Jorge Luis Borges, quienes más hayan pensado la poesía, y más aún, la hayan convertido en reflexión, filosofía, parábola, a la vez que le han devuelto, con toda su depuración, el estatuto primordial de palabra por la palabra: sonido, música, ritmo, esencia:

\footnotetext{
La poesía moderna es una tentativa de abolir todas las significaciones porque ella misma se presiente como el significado último de la vida y el hombre. Por eso a un tiempo es destrucción y creación del lenguaje. Destrucción de las palabras y de los significados, reino del silencio; y además, igualmente, palabra en busca de la Palabra (Paz 1990a: 7).
}

Evidentemente, la cita anterior alude a la búsqueda de un origen, del origen. La Palabra, con mayúscula, remite a la palabra primordial, perdida al ser expulsados del paraíso. La palabra, con minúscula, se refiere al lenguaje de la convención. La poesía utiliza dicho lenguaje, pero con el ánimo de trastocarlo, de fundirlo, y así encontrar de nuevo la palabra primera: la crítica del paraíso se llama lenguaje: “(...) la crítica del lenguaje se llama poesía”, apuntará Paz en una de sus citas ya canónicas (1990c: 96).

En este sentido, Octavio Paz puede ser considerado uno de los poetas y teóricos más importantes del siglo XX. Su síntesis de la tradición poética (específicamente moderna), tanto en su poesía como en sus ensayos, se convierte en una fuente ideal para el conocimiento del fenómeno que queremos estudiar: su visión del amor y de la poesía.

\section{2. De la poesía y del amor: analogía}

Un poema reproduce el universo: sus formas y sus ritmos. ¿Un objeto? Podríamos ver en esta idea un resabio del formalismo o del estructuralismo; sin embargo, debemos entender ese objeto como una máquina productora de significantes: siempre nuevos y distantes. La idea de los signos en rotación (Paz 1971b), tomada de manera fortuita, liga con la visión de una maquinaria, sus piñones y arandelas en movimiento, en producción. La diferencia es que la vastedad de esa máquina es sólo comparable con la maquinaria que mueve (¿rige?) el universo. Como un libro de arena, cada vez las posiciones son variantes de un sonido lejano que se escucha y jamás se repite; como un infinito juego de ajedrez, donde cada movimiento implica 
infinita cantidad de movimientos similares para contrarrestarlo. Esta noción es compartida por la mayoría de teóricos en la actualidad, como bien señalaba Umberto Eco: "l'œuvre d’art est un message fondamentalement ambigu, une pluralité de signifiés qui coexistent en un seul significant"3 (1965: 9).

El poema es tiempo y espacio: es el espacio de un momento inabarcable e innombrable, pero cercano y terreno. La aporía, la paradoja y la contradicción provienen de nombrar el mundo para abolirlo y tomar su lugar. La poesía se vuelve (in)habitable, y entonces se debe retornar al orden natural, original, génesis perpetua: caos. "-cada sociedad está edificada sobre un poema" (Paz 1998c: 91), un poema porque el lenguaje es el que construye la cultura (la constituye), para posteriormente destruirla y renovarla; sin embargo, esas sociedades deben permitirle al ser humano su condición de vida y existencia, para no arrojarlo al vacío inexorable de la nada. "La idea de correspondencia universal es probablemente tan antigua como la sociedad humana. Es explicable: la analogía vuelve habitable al mundo" (Paz 1998c: 102). Es a través de la comparación que el ser humano logra reconciliarse con su ser escindido, con su radical expulsión del paraíso. Mediante la parábola o la alegoría somos capaces, no de entender, que es fácil, sino de aceptar el universo como un mundo posible, finito y acorde con nuestra medida: la poesía entonces es la encargada de crear un espejismo porque es el discurso de la semejanza: la poesía (y el arte en general) es el intento del ser humano por volver a las praderas perfectas del nirvana, del útero: paraíso. Las diferencias quedan abolidas en el poema.

¿Pero por qué esta connotación? Surge de la constatación de la existencia del ser humano como una existencia trágica. Esta tragedia, atendiendo a la tradición clásica griega, surge justamente ante la concepción temporal, que es la que nos lleva a la conciencia de la muerte: la historia. Como oposición a un mundo en el que vivimos como seres en pecado, sin posibilidad de redención, presas del error y la fatalidad, la poesía hace posible imaginar (¿pensar?) de nuevo una existencia fuera del tiempo. De ahí la paradoja.

En "Piedra de sol", uno de los poemas más ambiciosos de la literatura, Paz intenta esa conjunción-explicación del mundo: una civilización perdida que pueda ser el eco de otra sociedad: el tiempo es una red de tejidos: los textos inventan el mundo y el mundo es en sí un texto donde los nombres de los amantes se confunden y conjuran la noche:

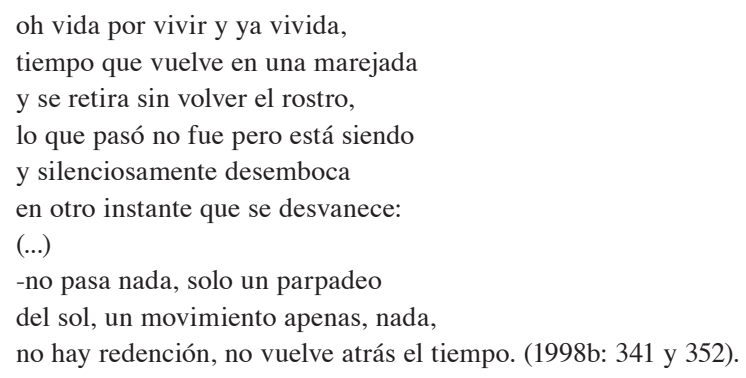

No hay redención. La analogía total, de haber alguna, ya no es tan siquiera la comparación entre dos cosas que incluso pueden aparecer a primera vista como disímiles, es la fusión completa de la cosa y el nombre: nominalismo panteísta: "stat rosa pristina nomine, nomina nuda tenemus"4 (Eco 1994: 471). Todo son solo nombres en la niebla fugaz de la memoria, nombres proferidos por Dios en el tiempo eterno e indisoluble. El universo no corresponde con el poema: es en sí mismo un poema, una creación del lenguaje: la palabra es la 
cosa: "El mundo no es un conjunto de cosas sino de signos: lo que llamamos cosas son palabras: una montaña es una palabra, un río es otra, un paisaje es una frase" (Paz 1998c: 108).

Sin embargo, no debemos considerar esta analogía como una indisolubilidad real. Como señalábamos antes, es apenas la creadora (el lenguaje lo es) del espejismo de lo idéntico, para no perecer a la irrefutable realidad de la diferencia: "La analogía es la metáfora en la que la alteridad se sueña unidad y la diferencia se proyecta ilusoriamente como identidad" (Paz 1998c: 109- 110).

Como bien apunta Paz, la analogía llega a ser confusa, justamente porque los signos se alteran, se reproducen: el significante deja de ser claro: en el libro del universo perdemos la página, releemos. Repetimos: nos confundimos: los puentes, el como de la analogía se pierde entre la bruma (Paz 1998c). "Carta de creencia" es otro poema que representa esa analogía, conjunción, comunión con el Todo, comunión de los amantes en el silencioso beso de los siglos.

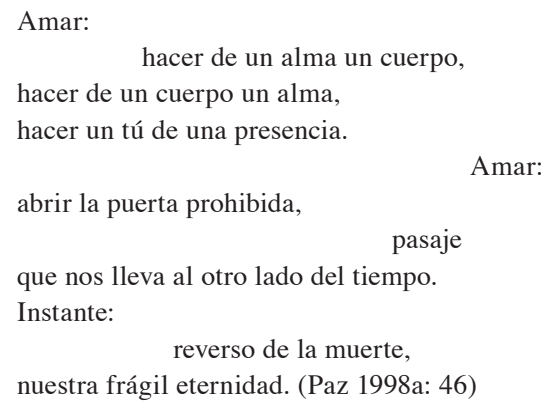

¿Y cuáles respuestas puede dar el amor al problema vital del ser humano? Ninguna. De ahí su radical desesperación. Amor y poesía son dos ramas del mismo sueño: abolir la cultura, los nombres, el yo y el vos, las palabras. Escribir y estar enamorado es lo mismo, no otra operación realiza aquel que dice estar enamorado, a pesar de no lograr nunca la sublimación. Señala Roland Barthes en su texto Fragmentos de un discurso amoroso: "Saber que no se escribe para el otro, saber que esas cosas que voy a escribir no me harán jamás amar por quien amo, saber que la escritura no compensa nada, no sublima nada, que es precisamente ahí donde no estás; tal es el comienzo de la escritura" (1996c: 122). Justamente por eso se escribe, porque hay una falta, un espacio vacío que permite la rotación infinita y dolorosa.

Así, el amor es quizá la única y la última justificación, en sí mismo, por sí mismo, como discurso, como tarea, como herramienta, escudo o pincel. Puesto que toda aspiración humana es ridícula o absurda, el amor es la única que nos redime, justamente por ser la más absurda de todas. A toda aspiración o empresa se le asigna un valor, un uso, un reducto práctico y seguro; no así al amor, espacio de locura y soledad. Al amor y a la escritura, aislados del sistema, parias del mercado, solo les queda su autoafirmación.

\footnotetext{
El discurso amoroso es hoy de una extrema soledad (...), separado no solo del poder sino también de sus mecanismos (...), arrastrado por su propia fuerza en la deriva de lo inactual (..), no le queda más que ser el lugar, por exiguo que sea, de una afirmación. Esta afirmación es, en suma, el tema del libro que comienza (Barthes 1996c: 11).
}

Y de este ensayo. 


\section{3. Del punto de partida}

Creo que todos los poetas de todos los tiempos han afirmado lo mismo: el deseo es un testimonio de nuestra condición desgarrada; asimismo, es una tentativa por recobrar nuestra mitad perdida. Y el amor, como la imagen poética, es un instante de reconciliación de los contrarios.

Octavio Paz

Las peras del olmo (1971a: 8)

El ser humano vive en la nostalgia, o bien, vive gracias a ella. Su tránsito por el mundo es el tránsito de un vacío, de una falta. Sus construcciones culturales son la sublimación de esa falta. Muchas veces (o siempre) no sabe de esa falta, por lo que además de buscar algo que no conoce, construye las justificaciones de esa búsqueda. El ser humano es un buscador que no sabe que lo es. En ese viaje doloroso, ambiguo, intenta también construir ese lugar del cual fue desterrado en el principio, y para construirlo debe primero destruir, abolir así sus propias construcciones culturales, porque intuye que son ellas mismas las cuales, como especie de maleza o nube de polución, le impiden ver nítidamente, en todo su esplendor, el paraíso perdido. Entonces, desde que existimos como sujetos del lenguaje, ese intento por regresar al paraíso es lenguaje, discurso en dos maneras o vertientes ${ }^{5}$ : el amor y la poesía. Así las cosas, lo que nos interesa mostrar son las relaciones entre el discurso amoroso y el discurso poético. En este sentido, trazaremos el mapa de tales relaciones, señalaremos las correspondencias entre el amor y la poesía en tanto discursos, pues efectivamente existe una correspondencia íntima entre ambos discursos, por cuanto ambos plantean una visión semejante que puede resumirse del siguiente modo: el ser humano, desgarrado en su origen, busca, imposible o incansablemente, la vuelta a ese origen perdido, lo cual sería posible mediante el amor: la comunión final con el Gran Todo, el Comienzo.

Ahora bien, ¿pueden la poesía y el amor lograr tal fin? No pueden. En realidad, la relación íntima entre ambos discursos radica en que ambos son discursos fundados en la falta, ambos tratan, de alguna manera, de vaciarnos del sentido cultural, de la convención por la que vivimos atados: amor y poesía son palabra, palabra nueva y vigorosa sí (aunque insuficiente), que busca regresarnos al Paraíso: el amor y la poesía, sólo momentáneamente, nos liberan. ${ }^{6}$

\section{Sobre la analogía}

No es el regreso a las aguas de origen sino la conquista de un estado que nos reconcilia con el exilio del paraíso. Somos el teatro del abrazo de los opuestos y su disolución, resueltos en una sola nota que no es de afirmación ni de negación sino de aceptación.

Octavio Paz

La llama doble (1995: 220- 221)

Octavio Paz, a partir de una estética romántica, construye textos que van más allá de las convenciones usuales: metatextos, espacios de unión entre la palabra y lo que nombra, espacios donde se conjugan la forma y el fondo: cómo vivo y cómo lo expreso. Todo ello logra Paz porque su poesía, igual que la del romanticismo, intenta fusionar una estética y una filosofía: "una manera de vivir y una manera de morir" (Paz 1998c: 91). "El pensamiento romántico -señala Paz- se despliega en dos direcciones que acaban por fundirse: la búsqueda de 
ese principio que hace de la poesía el fundamento del lenguaje y, por tanto, de la sociedad; y la unión de ese principio con la vida histórica" (1998c: 91). La poesía romántica es revolucionaria, pues busca devolver a la sociedad a su origen:

\begin{abstract}
De ahí que la poesía romántica pretenda ser también acción: un poema no solo es un objeto verbal sino que es una profesión de fe y un acto. Inclusive la doctrina del «arte por el arte», que parece negar esta actitud, la confirma y la prolonga: más que una estética fue una ética, y aun, muchas veces, una religión y una política. La poesía moderna oficia en el subsuelo de la sociedad y el pan que reparte a sus fieles es una hostia envenenada: la negación y la crítica. Pero esa ceremonia en las tinieblas también es una búsqueda del manantial perdido, el agua del origen (Paz 1998c: 91).
\end{abstract}

Es con este pensamiento que Paz identifica la poesía como una operación, un acto: la palabra produce, construye: "El poeta dice y, al decir, hace" (Paz 1998c: 93). También es en este punto donde Paz establece la relación entre la magia y la palabra: la poesía pensada y vivida como una operación mágica destinada a transmutar la realidad7. Prosigue Paz: "La analogía entre magia y poesía es un tema que reaparece a lo largo de los siglo XIX y XX, pero que nace con los románticos alemanes" (1998c: 94). A partir de este punto es donde podemos empezar a entender el concepto de analogía y su aplicación en el terreno poético. A fin de cuentas, todo nuestro trabajo no es otra cosa que analogía, desde lo formal hasta lo filosófico: la poesía es amor y el amor es poesía.

En su ensayo Las palabras y las cosas, intento por desentrañar las formas de pensar de nuestras sociedades, Michael Foucault analiza la relación entre el lenguaje y el mundo que nombra, y cómo este mundo es un tejido de signos, un texto en el que podemos leer las marcas, las señales, las huellas. Así, Foucault empieza por establecer la idea de semejanza como el mecanismo en el que se sustentaba el pensamiento:

\footnotetext{
Hasta finales del siglo XVI, la semejanza ha desempeñado un papel constructivo en el saber de la cultura occidental. En gran parte, fue ella la que guió la exégesis e interpretación de los textos; la que organizó el juego de los símbolos, permitió el conocimiento de las cosas visibles e invisibles, dirigió el arte de representarlas. El mundo se enrollaba sobre sí mismo: la tierra repetía el cielo, los rostros se reflejaban en las estrellas y la hierba ocultaba en sus tallos los secretos que servían al hombre. La pintura imitaba el espacio. Y la representación -ya fuera fiesta o saber- se daba como repetición: teatro de la vida o espejo del mundo... (Foucault 1996: 26).
}

Indica Foucault que los cuatro tipos de similitudes o semejanzas que se daban son, a saber: la convenientia, la aemulatio, la analogía y la simpatía. De ellas, la que nos interesa ahora es la analogía:

\footnotetext{
Viejo concepto familiar ya a la ciencia griega y al pensamiento medieval, pero cuyo uso ha llegado a ser probablemente diferente. En esta analogía se superponen la convenientia y la aemulatio. Al igual que ésta, asegura el maravilloso enfrentamiento de las semejanzas a través del espacio; pero habla, como aquélla, de ajustes, de ligas y de juntura. Su poder es inmenso, pues las similitudes de las que trata no son las visibles y macizas de las cosas mismas; basta con que sean las semejanzas más sutiles de las relaciones. Así aligerada, puede ofrecer, a partir de un mismo punto, un número infinito de parentescos. Por ejemplo, la relación de los astros con el cielo en el que centellean se encuentra de nuevo así: de la hierba a la tierra, de los vivientes al globo que habitan, de los minerales y los diamantes a las rocas en las que están enterradas, de los órganos de los sentidos al rostro que anima... (Foucault 1996: 30).
}

Como podemos ver, la analogía es metáfora por excelencia: en esto veo aquello, esto es aquello. Las relaciones son del orden de la naturaleza, de lo general a lo particular y viceversa: el universo es un conjunto de sonidos, señales, golpeteos que se vierten en una danza ritual. El universo es ritmo, repetición: todas las cosas son hermanas, viven en comunión, se prestan sus 
cualidades, se imitan, son y no son: envueltas en una sinfonía sin tiempo reproducen la palabra primera, crean mundos:

\begin{abstract}
Por medio de ella, pueden relacionarse todas las figuras del mundo. Sin embargo, existe en este espacio surcado en todas direcciones, un punto privilegiado: está saturado de analogías (cada una puede encontrar allí su punto de apoyo) y, pasando por él, las relaciones se invierten sin alterarse. Este punto es el hombre; está en proporción con el cielo, y también con los animales y las plantas... (Foucault 1996: 31).
\end{abstract}

La analogía descrita anteriormente es una de las más antiguas: el ser humano como repetición del universo. Justamente, esta analogía es la que permite estructurar, en la tradición cabalística, el árbol sefirótico.

Sin embargo, esta producción de semejanzas fue mermando cada vez más. El lenguaje analógico sería sustituido (ya desde mucho antes) por lenguajes más especializados, más lógicos, que pretendieron eliminar las marcas de la similitud. La episteme ilustrada, por ejemplo, borraría de un solo golpe el poder de las analogías, y replegaría al mundo de las supersticiones y banalidades metafísicas todo esfuerzo de la imaginación.

Octavio Paz también se va a referir al problema de la analogía en su texto Los hijos del limo:

Para los antiguos, el universo era la imagen visible de la perfección; en la noción circular de los astros y los planetas, Platón veía la figura misma del ser y del bien. Reconciliación del movimiento en la identidad: el girar de los cuerpos celestes, lejos de ser cambio y accidente, era el diálogo del ser consigo mismo (1998c: 167)

Ahora bien, ¿cómo descifrar o encontrar las analogías? Ellas están por todas partes, son las marcas o pistas que permiten la exégesis del mundo:

\footnotetext{
No hay semejanza sin signatura. El mundo de lo similar sólo puede ser un mundo marcado. «No es la voluntad de Dios -dice Paracelso- que permanezca oculto lo que Él ha creado para beneficio del hombre y le ha dado... Y aun si hubiera ocultado ciertas cosas, nada ha dejado sin signos exteriores y visibles por marcas especiales». (Foucault 1996: 35).
}

Desde este punto de vista, la labor de análisis es una semiótica del universo. Foucault establece que la semiótica no se pregunta por el significado de los signos, sino más bien por su ubicación, su forma de producción y medios para manifestarse.

Esta capacidad del mundo para mostrar/ocultar los signos deriva de la esencia misma del lenguaje: su separación del mundo natural, la distancia que lo separa de los objetos a los que se refiere:

\footnotetext{
Sin embargo, si el lenguaje no se asemeja de inmediato a las cosas que nombra, no está por ello separado del mundo; continúa siendo, en una u otra forma, el lugar de las revelaciones y sigue siendo parte del espacio en el que la verdad se manifiesta y se enuncia a la vez (Foucault 1996: 44) ${ }^{8}$.
}

Entonces, el lenguaje en sí es una aporía: intento y desilusión, lo otro y lo mismo: separado del mundo toma su lugar; separado del mundo es su único referente: el lenguaje sustituye al mundo, pero conocemos el mundo gracias al lenguaje. Esa es justamente la tragedia de Don Quijote, su mundo es un mundo de marcas, de signos. Su misión es desfacer entuertos literarios, lingüísticos; más aún, su mundo es lenguaje, literatura: Don Quijote no lee, Don Quijote vive, actúa el verbo:

Con todas su vueltas y revueltas, las aventuras de Don Quijote trazan el límite: en ellas terminan los juegos antiguos de la semejanza y de los signos; allí se anudan nuevas relaciones. Don Quijote no es el hombre extravagante, sino más bien el peregrino meticuloso que se detiene en todas las marcas de la similitud. Es el héroe de lo mismo (...) sin traspasar jamás las claras fronteras de la diferencia, ni reunirse con el corazón de la identidad (Foucault 1996: 53). 
Don Quijote buscará en la realidad la marca de los libros, y al no descubrirla, su frustración encontrará asidero también en ellos, porque según esos libros, será culpa de los encantadores que él no triunfe en su tarea. La analogía encuentra aquí su tope, su paradoja: para que una analogía funcione, según Foucault, esta debe rastrear el universo entero en busca de la última y más pequeña analogía, es decir, la analogía funciona por encadenamiento: si en esto veo aquello, en aquello veré lo otro y así sucesivamente, hasta caer en una forma de conocimiento arenoso (Foucault 1996). Así, el saber ha pasado por una serie de etapas que hicieron que, finalmente, la analogía desapareciese. Dicha desaparición será progresiva, desde la antigüedad hasta la modernidad 9 : desde que el ser humano era uno con el mundo hasta su completa alienación. Es en este sentido donde surge la figura del decir poético:

\footnotetext{
...el poeta es el que, por debajo de las diferencias nombradas y cotidianamente previstas, reencuentra los parentescos huidizos de las cosas, sus similitudes dispersas. Bajo los signos establecidos, y a pesar de ellos, oye otro discurso, más profundo, que recuerda el tiempo en el que las palabras centelleaban en la semejanza universal de las cosas: la Soberanía de lo Mismo, tan difícil de enunciar, borra en su lenguaje la distinción de los signos. (...) El poeta (...) tiene el papel alegórico, bajo el lenguaje de los signos y bajo el juego de sus distinciones bien recortadas, trata de oír el «otro lenguaje», sin palabras ni discursos, de la semejanza (Foucault 1996: 56).
}

Es decir, el poeta trata de borrar los límites, la convención, el signo socialmente aceptado, el signo que permite la interacción y provoca el espejismo de la comunicación: "La palabra designa, es decir, que en su naturaleza misma es nombre. Nombre propio ya que está dirigido hacia tal representación y hacia ninguna otra" (Paz 1995: 102). El poeta deshace los nombres, los diluye en una nueva marea lingüística:

\footnotetext{
La palabra poética es mediación entre lo sagrado y los hombres y así es el verdadero fundamento de la comunidad. Poesía e historia, lenguaje y sociedad, la poesía como punto de intersección entre el poder divino y la libertad humana, el poeta como guardián de la palabra que nos preserva del caos original: todas estas oposiciones anticipan los temas centrales de la poesía moderna (Paz 1998c: 66- 67).
}

La anterior afirmación desnuda la paradoja en la que habita el poeta: no es él quien nos libera de la convención, es él, cual equilibrista sin red, quien debe hacernos ver el paraíso y a la vez ocultárnoslo, porque solo él conoce los secretos, pero su tarea será la de salvaguardarlos. O dicho de otro modo, el poeta crea espejismos muy parecidos al paraíso, nada más:

\footnotetext{
Busco en la realidad ese punto de inserción de la poesía que es también un punto de intersección, centro fijo y vibrante donde se anulan y renacen sin tregua las contradicciones. Corazón-manantial.

La pregunta contiene dos términos antagónicos y complementarios: no hay poesía sin sociedad pero la manera de ser social de la poesía es contradictoria: afirma y niega simultáneamente al habla, que es palabra social; no hay sociedad sin poesía, pero la poesía no puede realizarse nunca como poesía, nunca es poética, (...) Condenados a una perpetua conjunción que se resuelve en instantánea discordia, los dos términos buscan una conversión mutua: poetizar la vida social, socializar la palabra poética. (...) Transformar la sociedad en comunidad creadora, en poema vivo; y del poema en vida social, en imagen encarnada (Paz 1971: 308).
}

El poeta vive así, encerrado, atrapado por dos posibilidades: "La palabra poética se sustenta en la negación de la palabra" (Paz 1971: 309). De esta manera, el poeta busca retornar al origen, pero aún más que eso, indica Paz: "La rebelión de los poetas románticos y la de sus herederos modernos no fue tanto una protesta contra el destierro de Dios como una búsqueda de la mitad perdida, descenso a esa región que nos comunica con lo otro" (1971: 323). Pero buscar esa región es tarea titánica, se podría afirmar, porque los signos que nos conducen a ella no son uniformes, a pesar de que así los queramos ver: 
En la dispersión de sus fragmentos... El poema, ¿no es ese espacio vibrante sobre el cual se proyecta un puñado de signos como un ideograma que fuese un surtidor de significaciones? Espacio, proyección, ideogramas: estas tres palabras aluden a una operación que consiste en desplegar un lugar, un aquí, que reciba y sostenga una escritura: fragmentos que se reagrupan y buscan constituir una figura: un núcleo de significados (Paz 1971: 324- 325).

Entonces, el poema es un espacio donde confluyen diversas fuentes, donde se abrazan los opuestos en una nota de reconciliación: es el espacio analógico por excelencia: "La visión romántica del universo y del hombre: la analogía, se apoya en una prosodia (concibe al mundo como ritmo: todo se corresponde porque todo ritma y rima. La analogía no es sólo una sintaxis cósmica: también es una prosodia" (Paz 1998c: 97).

Por otro lado, la manifestación de la analogía se da en la metáfora, conjunto de palabras que sustituyen al mundo y lo vuelven texto por descifrar. Así, el poeta es el encargado de decodificar ese mundo, especie de sabio antiguo, alquimista ${ }^{10}$ que transmuta la realidad gracias a las palabras.

Finalmente, debemos enfatizar en el hecho de que la analogía existe justamente porque las cosas, sus nombres o las palabras, no son iguales. La analogía permite que nos encontremos en este mundo, que lo aceptemos, que lo hagamos nuestro. Es una manera de ver el mundo, de comprenderlo, de soportarlo. Sin el como de la analogía, no lograríamos sobrevivir a la monstruosa visión del origen, del Gran Todo. Sabemos que ese origen está perdido, tratamos de regresar a él mediante la palabra y a la vez mediante su disolución. La analogía es el teatro del mundo, donde actúa el verbo, donde es proferido, como medio para reencontrarnos, quizá, con nadie más que con nosotros mismos, o bien, la analogía tal vez sea la posibilidad de soñarnos alteridad, de ilusionarnos con la idea de otro que me complementa y me ayuda, que me alimenta y me completa. Apunta Castañeda en su texto "Sed de otredad", acerca de la obra de Octavio Paz:

El laberinto de la soledad abre con un epígrafe de Antonio Machado, donde se sugiere el problema clave de la obra completa de Paz. Recuerdo las palabras del filósofo imaginario Abel Martín: "Lo otro no existe: tal es la fe racional, la incurable creencia de la razón humana. Identidad = realidad, como si, a fin de cuentas, todo hubiera de ser, absoluta y necesariamente, uno y lo mismo. Pero lo otro no se deja eliminar; subsiste, persiste; es el hueso duro de roer en que la razón se deja los dientes. Abel Martín, con fe poética, no menos humana que la fe racional, creía en lo otro, en 'la esencial Heterogeneidad del ser', como si dijéramos en la incurable otredad que padece lo uno". Esta sospecha es el detonador de una serie de dudas, ¿qué sentido entraña ese hueso duro de roer?, ¿de dónde nace esa fe poética que cuestiona la incurable creencia racional? ¿Por qué indagar en la incurable otredad del ser? (1998).

La analogía no necesariamente iguala las cosas o las devuelve a su lugar de origen. Simplemente las compara y las hace accesibles. Don Quijote, nuevamente, nos alecciona:

\footnotetext{
Porque veas Sancho, el bien que en sí encierra la andante caballería y cuán a pique están los que en cualquier ministerio de ella se ejercitan de venir brevemente a ser honrados y estimados del mundo, quiero que aquí a mi lado y en compañía de esta buena gente te sientes, y que seas una misma cosa conmigo, que soy tu amo y natural señor; que comas en mi plato y bebas por donde yo bebiere, porque de la caballería andante se puede decir lo mismo que del amor se dice: que todas las cosas iguala" (Cervantes y Saavedra 2004: 96).
}

Por fin llegamos, mediante Don Quijote y su invitación a Sancho, al encuentro del discurso amoroso. El amor, analogía final, es la redención de los opuestos. El abrazo intenta fusionar los cuerpos, el beso aglutinar la savia humana, la palabra empatar a los espíritus. El amor es el intento por abolir las convenciones porque es acto, performance. Para Barthes, te-amo ni siquiera es ya "metáfora de nada" (1996: 235), es acción pura y simple, primordial. 
"En cierta manera -paradoja exorbitante del lenguaje-, decir te-amo es hacer como si no hubiese ningún teatro de la palabra, y esa expresión es siempre verdadera (no hay otro referente que su proferición: es un preformativo)" (Barthes 1996: 235). Así, el amor será la realidad última (y la primera), aspiración absoluta del poema (y del poeta).

El poeta, en su operación de lenguaje, desnudará, en última instancia, su trágica realidad: es ser mortal, perdido en la historia, en el tiempo sucesivo. Su vida es una ironía, una contradicción que trata de ser curada mediante la analogía, imagen del tiempo cíclico. La poesía es una máscara, pantalla, un tapón para encubrir el vacío que implica la palabra poética:

\footnotetext{
La ironía es la herida por la que se desangra la analogía; es la excepción, el accidente fatal, en el doble sentido del término: lo necesario y lo infausto. La ironía muestra que, si el universo es una escritura, cada traducción de esa escritura es distinta, y que el concierto de las correspondencias es un galimatías babélico" (Paz 1998c: 111).
}

Similar preocupación ya había externado Foucault, al considerar que el pensamiento analógico era arenoso y prácticamente infinito. Tragedia del ser humano: al intentar desentrañar los misterios del universo no hace otra cosa que perderse en la maraña de los signos porque ha olvidado el lenguaje primordial (¿el del silencio?), la clave para desentrañar la analogía, en lugar de perpetuarla y desenrollarla infinitamente: "La palabra poética termina en aullido o silencio: la ironía no es un palabra ni un discurso, sino el reverso de la palabra, la no-comunicación" (Paz 1998c: 111). Esa es la revelación última y la única a la que tenemos acceso: la nada, como el descubrimiento del caballero medieval de Det Sjunde Inseglet (El séptimo sello) (Bergman 1957). Ante semejante horror ${ }^{11}$, ante semejante descubrimiento, el ser humano se despeña por un acantilado, un abismo, un vacío sin fin: "Un saber que no consiste en la contemplación de la alteridad en el seno de la unidad, sino en la visión de la ruptura de la unidad. Un saber abismal, irónico" (Paz 1998c: 113). En este punto, la poesía y el amor funcionarán como máscaras de la nada.

La tragedia del ser humano, presenciada burlonamente por los dioses, es una contradicción permanente: entre ser y no ser, entre decir y hacer, entre la sociedad y la naturaleza. Todos los signos son opuestos, contradictorio, paradójicos. No hay solución, escape o salida.

\footnotetext{
La inmortalidad temporal del alma del hombre, esto es, su eterno sobrevivir tras la muerte, no sólo no está garantizada en modo alguno, sino que, ante todo, tal supuesto no procura en absoluto lo que siempre se quiso alcanzar con él. ¿Se resuelve acaso un enigma porque yo sobreviva eternamente? ¿No es, pues, esta vida eterna, entonces, tan enigmática como la presente? La solución del enigma de la vida en el espacio y el tiempo reside fuera del espacio y del tiempo? (Wittgenstein 2000: 179- 181).
}

Sometidos a la tortura del tiempo, no queda más que observar el paso de las horas, la llegada de las parcas, y en ese instante, resolver el dilema existencial de manera afirmativa: las palabras me han hecho caer y por ellas habré de redimirme. El silencio sería la forma más pura de poesía, porque podríamos escucharnos finalmente, pero no podemos escapar de la torre de Babel: la poesía y el amor son apenas paliativos contra la muerte.

Los poetas de todas las épocas y culturas 12 "han opuesto al tiempo lineal del progreso y de la historia, el tiempo instantáneo del erotismo, el tiempo cíclico de la analogía o el tiempo hueco de la conciencia irónica" (Paz 1998c: 155), todo con el fin de reconciliarnos con nuestro origen perdido. Esta reconciliación es, a fin de cuentas, con nosotros mismos, es la aceptación de nuestro "error", de nuestro "pecado original". Si ya no aspiramos a la disolución del sentido y, por ende, de la cultura, con el ánimo de retornar al paraíso, pues sabemos que es tarea vana, al menos aspiramos a reproducir, en su seno, como crítica y diatriba, una imagen del paraíso, donde ya no deambulemos, perdidos y añorando, sino resignados y a lo mejor satisfechos, por 
haber descubierto el secreto último antes de la muerte: "Sentimos que aun cuando todas las posibles cuestiones científicas hayan recibido respuesta, nuestros problemas vitales todavía no se han rozado en lo más mínimo. Por supuesto que entonces ya no queda pregunta alguna; y esta es precisamente la respuesta" (Wittgenstein 2000: 181 y 183). No hay respuesta posible, excepto una respuesta de sordos, es decir, franquear la posibilidad y continuar escribiendo.

Somos un fragmento del mundo, apenas, y como tal podemos vivir, tranquilos de haber realizado nuestra tarea (¿cuál?): “La solución del problema de la vida se nota en la desaparición de ese problema. (¿No es ésta la razón por la que personas que tras largas dudas llegaron a ver claro el sentido de la vida, no pudieron decir, entonces, en qué consistía tal sentido?" (Wittgenstein 2000: 183). Siempre queda una pregunta última sin respuesta y aún con la muerte no sabremos si ella logrará responderla. Ahí es donde el ser humano se reconcilia consigo mismo:

\footnotetext{
A pesar de todos los males y todas las desgracias, siempre buscamos querer y ser queridos. El amor es lo más cercano, en esta tierra, a la beatitud de los bienaventurados. Las imágenes de la edad de oro y del paraíso terrenal se confunden con las del amor correspondido: la pareja en el seno de una naturaleza reconciliada. (...) Reinventar el amor es reinventar a la pareja original, a los desterrados del Edén, creadores de este mundo y de la historia.

El amor no vence a la muerte: es una apuesta contra el tiempo y sus accidentes. Por el amor vislumbramos, en esta vida, a la otra vida (...) a la vivacidad pura: (Paz 1998c: 220).
}

La pareja, el otro, yo mismo. Somos espacios del sueño, de la invención y de la imaginación. El ser humano, arrojado a este mundo del tiempo finito, es un buscador. Probablemente no sabe qué buscar o por qué ha de hacerlo, solo asume su tarea, su trabajo cotidiano, sus creaciones, sus ciudades y sus guerras, sus desdichas y sus amores, sus esperanzas y sus desilusiones: espejismos de lo eterno. Todo se justifica cuando escuchamos el te-amo: sílaba última que nos devuelve al principio "Antes del tiempo" (Paz 1998d: 753) y nos reconcilia por fin: "En tu respiración escucho/ la marea del ser,/ la sílaba olvidada del Comienzo." (Paz 1998d: 754).

\section{A manera de coda}

¿No es cosa extraña que de tantos poetas que han hecho himnos y cánticos en honor de la mayor parte de los dioses, ninguno haya hecho el elogio de Eros, que sin embargo es un gran dios?

Platón

"Simposio (Banquete) o de la erótica", Diálogos (1975: 354).

Al iniciar el banquete, Erixímaco recuerda la indignación de Fedro debido al hecho de que no existan cantos dedicados a Eros. Erixímaco propone entonces, con el ánimo de pagar tributo al amor, se discuta en la mesa sobre tal tema (Platón 1975). Esta fábula nos remite nuevamente a nuestro contexto y a uno de los puntos de partida del presente trabajo: el amor está de lado, censurado, apartado, exiliado de todo sistema de pensamiento y de sí mismo. Sin embargo, no podemos menos que aceptar que justamente esa es (y debe ser) su condición. De otra manera, sería apenas un discurso acaparado por el poder, por las instancias burocráticas, tal y como sucede con el comercio, Hollywood y demás. Muchos dirán (incluso resulta curioso que en el mundo griego no hubiese) que eso no es cierto, que el amor es un tema cotidiano. Y tienen razón. Del amor se habla, pero en su visión doxológica, como tarjeta postal o souvenir. 
Del amor como cuestionamiento, como transgresión (sexualidad y erotismo incluidos), se erige una prohibición, un veto.

Cuando Octavio Paz habla de amor y poesía, sus alcances se elevan por encima del tema en sí y alcanzan el terreno de la ética, del valor del ser humano, un ser humano despojado de su humanidad (por la religión, la economía, la política y la tecnología): la apuesta de Paz es por la dimensión individual y comunitaria del ser humano como ser social y ser histórico. Castañeda, en su ensayo "Sed de otredad", analiza bastante acertadamente estas cuestiones:

No cabe duda que la cuestión principal en La llama doble no era el significado de la pasión amorosa ni la disyuntiva entre erotismo y amor, Octavio Paz confabula un testimonio en defensa del valor de la persona. Y cuál mejor que uno donde apela al sentido de la persona amada, como afirmó en una línea que es todo un aforismo, "el amor es una apuesta, insensata, por la libertad. No la mía, la ajena." (Castañeda 1998).

Entonces, al problema del origen, del destierro primero que nos convierte en seres en falta, deseantes, insatisfechos, Octavio Paz agrega la problemática de nuestro tiempo. Su estética es una estética de afirmación, de construcción, basada en la crítica de los significantes que posibilitan la existencia del ser como ser cultural. Su poesía es analogía, abrazo y aceptación: si fuimos despojados del origen, seremos capaces de reconstruir un paraíso propio, con la palabra y a pesar de la palabra. El amor y la poesía son solamente discursos, textos sumados al conjunto mayor de todos los textos del mundo, pero capaces de hacernos vislumbrar, aunque sea por un segundo, la maravilla del Edén: "Porque la poesía, que parte de la consciencia de nuestra mortalidad, nos lleva a la contemplación de la inmortalidad del amor" (Paz 1971: 8). En "Carta de creencia", leemos:

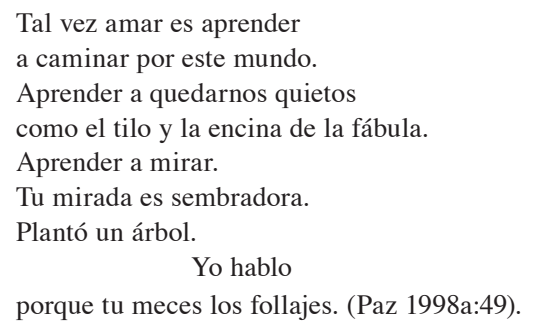

La poesía es el reverso de la palabra, su vacío fatal; el amor es el reverso del alma, la nada absoluta; pero también ambos son génesis, fecundidad: hacen brotar de nuestros labios, en la palabra y en el beso, el acorde perfecto, la música universal que nos hace deleitarnos, contemplar la eternidad y aceptarnos, unos a otros, en este mundo: "En uno de sus libros más hermosos, El loco amor, Breton ha puesto de relieve la naturaleza absorbente, total, del amor único: «delirio de la presencia absoluta en el seno de la naturaleza reconciliada.»” (Paz 1971: 147).

Nuestro trabajo ha intentado observar todos esos detalles, escuchar los ecos perdidos en la aurora del mundo; ha intentado hablar de dos tipos de discurso que, sustentados en el lenguaje, nos hacen dudar de él y nos hacen crear. El amor como una herida oculta que nos corroe, como una flor de sangre: dualidad mortal. La poesía como una vida y una visión.

Hemos tratado de tender los puentes para iniciar el análisis de la poética de Octavio Paz como una fusión el discurso poético y el discurso amoroso. Los textos pacianos, entendidos como metapoesía, avanzan más allá de sus postulados para ubicarnos en una atmósfera particular, única. Son maneras de ver el mundo y de entender el mundo: son el mundo, un universo, un conjunto de metáforas y analogías. Octavio Paz lleva al límite la conjunción de los géneros, de los estilo, de las filosofías: La llama doble y "Carta de creencia", 
por ejemplo, son una y la misma, dos caras de una moneda, dos extremos que en el tiempo circular se confunden y se tocan, se trastocan: el ensayo paciano es poético y es una apuesta por la dimensión del ser humano en su coyuntura existencial y social; su poesía es reflexión y una manera de entendernos y aceptar la comunión de los opuestos. La poética paciana une ética y estética; como para los románticos, la poesía es una forma de vida y una forma de arte. Su poesía encierra el germen de su propia construcción. Cada poema y cada ensayo van dejando las huellas, las marcas de su estructura. Esta operación se llama creación; y su fruto: cuadro, poema, tragedia. Toda creación transforma las circunstancias personales o sociales en obras insólitas. El hombre es el olmo que da peras increíbles" (Paz 1971: 7). Sí, el poeta habla, transmuta las palabras, es el alquimista del verbo (Rimbaud y su legión aguardan) y Paz ha hecho lo propio: palabra en el tiempo y contra el tiempo.

En Los hijos del limo Paz analiza el periplo de la poesía moderna, desde los románticos hasta los poetas del siglo XX. En esa curva histórica observa como la analogía pretende reconciliarnos con la naturaleza y como la ironía desnuda tal analogía. Paz apuesta entonces por la posibilidad de inventar el mundo: "cree" en la analogía. En "Carta de creencia", por ejemplo, Paz propone que la mirada es más fecunda que la palabra misma, es una estética y una ética que nos llevan al silencio, pero no al silencio estéril, sino al silencio original de las cosas, cuyo rumor se extiende por los montes y los mares: "Lo inexpresable, ciertamente, existe. Se muestra, es lo místico" (Wittgenstein 2000: 183). Es curioso que un filósofo como Wittgenstein ${ }^{13}$, quien produce una obra sobre la lógica y en contra (¿en contra?) de la metafísica llegue a revelaciones que solo la poesía ha logrado (quizá sea ese su valor) ¿O no será más bien que no podemos escapar a la poesía y a la metafísica? Wittgenstein propone, a mi gusto, una estética de la prudencia.

En La llama doble Paz elabora largas digresiones sobre el momento histórico de finales del siglo XX, con sus vueltas y revueltas hacia el futuro y sus aspiraciones tecnócratas. Paz establece que el siglo xx (y debemos agregar la modernidad) arrojó de su seno todo lo que no fuese científico, y así, cuando creía haber derribado los ídolos con el mazo de la razón, descubre, entre asombrado y triste, que las artes, la filosofía y la religión no pueden estar exiliadas, sino que deben formar parte del debate continuo, de la discusión de las ideas, como ejercicio de la libertad del ser humano.

La necesidad de regodearnos en un paraíso no tiene porqué ser metafísica, puede ser sencillamente humana, en este tiempo, aquí y ahora. A fin de cuentas, el tiempo siempre es el tiempo del ahora, tiempo del comienzo y por lo tanto tiempo de nuevas oportunidades:

La muerte no es un acontecimiento de la vida. No se vive la muerte.

Si por eternidad se entiende, no una duración temporal infinita, sino intemporalidad, entonces vive eternamente quien vive el presente. Nuestra vida es tan infinita como ilimitado es nuestro campo visual (Wittgenstein 2000: 179).

La respuesta final sobre las facultades del amor y la poesía para devolvernos al paraíso se resuelven en un tono revelador y casi mágico (aunque sin abandonar su lado irónico). Octavio Paz, citado por Enrico Mario Santí (2001), su amigo y prologuista, nos dice:

Todos y todas, todo/ es hechura del tiempo que comienza y se acaba/ Árbol de sangre, el hombre siente, piensa, florece/ y da frutos insólitos, palabras./ Se enlazan lo sentido y lo pensado,/ -tocamos las ideas: son cuerpos y son números. El hombre y la galaxia regresan al silencio./ ¿Importa? Sí/ -pero no importa:/ sabemos que ya es música el silencio/ y somos un acorde del concierto. 


\section{Notas}

1. La condición desgarrada del ser humano y su búsqueda de reconciliación.

2. Con esto no tratamos de excluir lo que representa un Rubén Darío, por ejemplo, quien introdujo a los malditos franceses a los escritores latinoamericanos y además generó el primer movimiento literario atribuido a América; o a un José Martí; pero sí hacemos una división entre crítica y poesía. Especialmente por las características de la poesía dariana o martiana. Es decir, la característica de la modernidad es la crítica, entendida esta en un sentido muy amplio, tal como apunta Paz (1998c).

3. En referencia al título del libro de Octavio Los signos en rotación y otros ensayos.

4. "La obra de arte es un mensaje fundamentalmente ambiguo, una pluralidad de significados que coexisten en un solo significante" (Trad. del autor).

5. "El nombre de la rosa se mantiene prístino, nada más tenemos nombres" (Trad. del autor).

6. El misticismo también suele compararse con el éxtasis amoroso y poético, como intento de vaciar los significantes.

7. Un árbol está en el centro del paraíso, por ese árbol fuimos expulsados. Relación metafórica: uno de los libros de Octavio Paz se llama Árbol adentro, y en los dos últimos versos de su último poema, finaliza: "Yo hablo/ porque tú meces los follajes" (Delta de cinco brazos, 1998a: 118) La constante presencia de la figura del árbol es señalada por Elena Poniatowska (1998). Por su parte, el poema en prosa El mono Gramático revela este juego de las palabras como bosque, follaje, ramas, maleza y de la poesía como decodificadora de ese bosque verbal: poda lírica para volver al tiempo antes del tiempo; y aun así, la maleza vuelve a crecer.

8. $\quad$ Es desde este punto de vista que la poesía se convierte en ética, porque la estética es activa, produce, y por lo tanto tendrá consecuencias.

9. Foucault indicará, más adelante, que "En el pensamiento moderno no es ya concebible tal origen: se ha visto cómo el trabajo, la vida y el lenguaje adquirieron su propia historicidad, en la cual están hundidos: así, pues, no podía enunciar jamás verdaderamente su origen, si bien toda su historia como que apunta, desde el interior, hacia él" (1996: 320).

10. Octavio Paz establece que el pensamiento analógico resurge con el romanticismo alemán (1998c).

11. No es gratuito que hagamos mención a la numerología y a la Cábala, pues el romanticismo bebió suficiente de las tradiciones ocultistas o secretas, principalmente aquellas que fueron formas de pensamiento durante la Antigüedad y la Edad Media.

12. Nietszche se refiere al "horror" que atrapa al hombre turbado cuando se equivoca en las formas del conocimiento de un fenómeno. "Si a este horror le agregamos el agradable éxtasis que se eleva de lo más profundo del hombre y aun de la Naturaleza al romperse el mismo «principium individuationis», comenzamos entonces a entrever en qué consiste el «estado dionisiaco», que comprenderemos mejor aún por la analogía de la «embriaguez»" (1992: 26- 27).

13. Paz circunscribe esto a los poetas del siglo XX; sin embargo, es imposible no relacionar estas características con el pensamiento o la imaginación de diversas culturas y épocas. 
14. 6. 54 Mis proposiciones esclarecen porque quien me entiende las reconoce al final como absurdas, cuando a través de ellas -sobre ellas- ha salido fuera de ellas, (tiene, por así decirlo, que arrojar la escalera después de haber subido por ella).

Tiene que superar estas proposiciones; entonces ve correctamente el mundo.

15. Todas las direcciones fueron revisadas por última vez el 25 de julio de 2005 y se encontraban actualizadas.

\section{Bibliografía}

\section{Libros de Octavio Paz:}

1990a. Corriente alterna. $19^{\circ}$ ed. México D. F.: Siglo Veintiuno editores.

1990b. El arco y la lira. $7^{\circ}$ reimp. de la $3^{\circ}$ ed. México D. F.: Fondo de Cultura Económica.

1990c. El mono gramático. $3^{\circ}$ ed. Barcelona: Seix Barral.

1986. El signo y el garabato. Joaquín Mortiz (ed.). $2^{\circ}$ reimp. de la $2^{\circ}$ ed. México D. F.

1995. La llama doble. $5^{\circ}$ ed. Barcelona: Seix Barral.

1994. La otra voz. $3^{\circ}$ ed. Barcelona: Seix Barral.

1971a. Las peras del olmo. Barcelona: Seix Barral.

1971b. Los signos en rotación y otros ensayos. Madrid: Alianza editorial.

1998a. Delta de cinco brazos. Barcelona: Galaxia Gutemberg.

1998b. Libertad bajo palabra. $2^{\circ}$ ed. Barcelona: Cátedra, Letras hispánicas.

1998c. Los hijos del limo. $5^{\circ}$ ed. Barcelona: Seix Barral.

1998d. Obra poética (1935- 1988). Barcelona: Seix Barral.

\section{Sobre Octavio Paz ${ }^{15}$}

Castañeda, Juan C. 1998. "Octavio Paz: sed de otredad”. En: Etcétera, 277 (revista digital), http://www.etcetera.com.mx/1998/277/cjc0277.htm. 
Poniatowska, Elena. 1998. Las palabras del árbol. Barcelona: Plaza y Janés.

Pujol, Óscar. "El mono gramático y el sabio alquimista. Algunas reflexiones en torno a la poética de Octavio Paz en El mono gramático". En: http://www.svabhinava.org/abhinava/ OscarPujol/Abhinava-OactavioPaz.html.

Santí, Enrico Mario. 2001. Respuesta y reconciliación de Octavio Paz. En: "Jornada semanal”, 346 (revista digital), UNAM. En: http://www.jornada.unam.mx/2001/oct01/011021/ sem-enrico.html.

\section{Referencias generales}

Barthes, Roland. 1996. Fragmentos de un discurso amoroso. $12^{\circ}$ ed. Madrid: Siglo XXI editores.

Béguin, Albert. 1993. El alma romántica y el sueño. Ensayo sobre el romanticismo alemán y la poesía francesa. $2^{\circ}$ reimp. Madrid: Fondo de cultura económica.

Bergman, Igmar. 1957. Det Sjunde Inseglet (El sétimo sello). Suecia: Swedish Film Production.

Cervantes, Miguel de. 2005. Don Quijote de la Mancha. $3^{\circ}$ reimp. México D. F.: Alfaguara.

Eco, Umberto. 1994. El nombre de la rosa. Barcelona: RBA Editores.

1979. L' œuvre ouverte (La obra abierta). France: Éditions du Seui.

Foucault, Michael. 1996. Las Palabras y las Cosas. Madrid: Siglo XXI Editores.

Gerber, Daniel. 1989. "Poesía y psicoanálisis: encuentro en el desencuentro”. En: el Simposium Literatura y Psique, Jalapa, Veracruz.

Kaplan, Aron. 1994. Sefer Yetzirah. El libro de la creación. Madrid: Editorial Mirach.

Nietzsche, Friederich. 1992. El origen de la tragedia. $13^{\circ}$ ed. México: Espasa-Calpe.

Platón. 1975. Diálogos. $15^{\circ}$ ed. México D. F.: Editorial Porrúa.

Satz, Mario. 2006. "El árbol de la vida y el árbol de los filósofos”. En: http://homepage.mac. com/eeskenazi/arbolvida.html. Revisado el 26 de febrero de 2006.

Wittgenstein, Ludwig. 2000. Tractatus logico-philosophicus. Madrid: Alianza Editorial. 
